\title{
Modernization of Contemporary Chinese Culture from Philosophical Perspective
}

\author{
Xiaohong Kang \\ Xi'an International University, Xi'an, 710077, China
}

Keywords: Philosophical perspective, Chinese culture, Modernization

\begin{abstract}
Contemporary culture in China is in a crucial transition period from traditional to modern, agricultural civilization also appeared to have a certain degree of transition influenced by industrial civilization, which corresponds to the evolution of social civilization, ultimately reflects China's transformation and development trend of contemporary culture.From the view of philosophy, cultural globalization and modernization trends build important context for our contemporary cultural values reconstruction, so to study of modernization of contemporary Chinese culture, we should explore value restructuring context on the basis of development status quo, identify cultural transformation path in modern society, guide the development of contemporary Chinese culture to the right path.
\end{abstract}

\section{Introduction}

With further development of reform and opening up, economic exchanges and cooperation with the rest of the world are strengthened, economic internationalization has been improved; in the meantime, our culture are inevitable under the influence of the mainstream ideology in Western developed countries, there have been some conflicts, collision, penetration and fusion in the process of cultural development which have a corresponding influence on China's contemporary culture.Overall, from the philosophical perspective, pluralistic developmental trend of contemporary Chinese culture under the corrosion of foreign culture was clearly demonstrated; traditional culture, western culture and the mainstream Socialist culture are thriving together, becoming three pillars as skeleton of the modern Chinese culture.So promoting the modern transformation of Chinese culture in the new era should start from a philosophical perspective and on the precondition of analysis of philosophical basis and mechanism of modern Chinese culture, guide the direction of cultural development, resist adverse foreign cultural erosion, and promote better development of Chinese culture in contemporary society.

\section{Philosophical basis of mainstream Socialist culture and Chinese Marxism in China}

Simply said, Socialist mainstream culture is the thematic culture in Chinese socialist society.It reflects mainstream ideology formed in the process of Socialist system construction and development. More than 60 years, China Socialist mainstream culture after development and evolution in all history period, always insists on the right leadership of Marx doctrine, insists on promoting essence of Chinese revolution, it had extremely important positive effect on China social and spiritual construction.This, to a certain extent, demonstrated the objective requirement of China's Socialist system on cultural construction; it's also the inevitable development direction of Socialism values.In recent years, with China's strong political and economic power, the mainstream culture in modern society also began to show specific content and forms of expression, and promotes the modernization of contemporary social and cultural construction. This article analyzes on their specific content and unique forms of expression: first, the dominant culture. This sort of culture content is the essence of Socialist mainstream culture, represents its specific culture nature and future development direction. Chinese Central Government and socialist party carried out series of educational publicity activities among theoretical research, educational field and corresponding media in recent years to promote leading culture, which greatly strengthened its publicity advantage in national social life, keeping its absolute advantage in collision of China modern culture and world culture.Second, guiding culture. 
This sort of culture is the necessary complement to dominant culture; it can assist construction of Socialist main culture and truly reflect the inclusive features of mainstream culture on other culture.

Under the influence of the Socialist market economy in China, convergence of various cultural forms and media forms, China's mainstream culture in our society faces challenge from other types of cultures. So, if Chinese culture wants to get further development in new era, it cannot simply influence the public in doctrine and cramming ways, it should utilize various culture carriers and process traditional mainstream culture into popular ones, so that the public can understand the basic connotation of Socialist mainstream culture from simple event, identify with traditional culture, and contribute for development and transformation of Chinese culture.

\section{Infiltration of Popular culture and Western philosophical thoughts in modern society,}

In contemporary society, the largest tributary of the culture should be popular culture, since 1980 in 20th century, media start to promote soothing, warm and featured recreational culture through various forms to the public; it showed penetrating features of popular culture, it also highlights inclusiveness of the mainstream Socialist culture. In research process of popular culture, we need to note that, although popular culture and mass culture are similar, but they are not the same, essentially, spread and development of mass culture concerns more of its form, while popular culture concerns the popularity of its content, and has unprecedented impact in extremely strong on social mass of their work and life [1].So, in the process of modernization of Chinese culture, we should pay attention to the double effects of popular culture: on one hand, popular culture can adapt to the value of socialist market and it has its own vitality and growth in modern society and affect the public of their value concept positively; on the other hand, improper development of popular culture would easily put the principle of material first to the front, leading to spirit lost. Therefore, research should be directed towards concrete analysis of concrete problems, to avoid occurrence of extreme rejection or extreme advocates.

The most significant manifestation of popular culture is its commercial and marketing features, which conforms to the idea of commercial benefit. In terms of communication channels, it can make full use of rich forms of contemporary media and have a strong impact on the development of mainstream culture. Popular culture not only encourage the public to develop their own personality, it also advocates a cathartic way to maintain social harmony, more importantly, popular culture has the most extensive access to culture in Western society, it definitely contains certain western philosophy, which has an important influence on the development of Chinese culture. Take existentialism as an example, existentialism is the most influential humanistic philosophy in the western world, after promotion by Jean-Paul Sartre and others after World War II, it's starting to affect various aspects of western social life [2].Existent in existentialism does not refer to the spirit in general philosophy, but refers to the existence of individual human beings in the social life, their research focused on existence, that's why it's called existentialism human study. In 1980 of last century, Existentialism starts to emerge in China and were welcomed by college students and got popular; it has infiltrated the society in various aspects and influenced the value of public.But we should aware that popular culture can affect the society both ways: on one hand, positive contents in popular culture such as fighting spirit regardless of his social background and love concept of being together, can help the public establishing correct life value; but on the other hand, there are also dross thoughts in popular culture such as extreme doctrine of egoism , inert thought of living for today and cult thought, spread and popularity of these are bound to adversely affect social development.So, in the process of modernization of Chinese culture, we should pay more attention to the influence of popular culture and western philosophy, and actively guide the positive aspects, abandon dregs, make modernization of Chinese culture a contributing force for the construction of a harmonious socialist society. 


\section{Cultural transformation and value reconstruction in modern Chinese society from the philosophical perspective}

\section{Chinese and foreign cultures are complementary to each other}

Cultural diversity becomes more evident in today's society, complement various cultures with each other is the motivational inspiration for further development. Complement Chinese with foreign cultures simply means borrow and supplement with each other according to their need for mutual complement and reference [3].Transformation and development of Chinese culture from traditional to contemporary society is a complicated systematic project, therefore, we can start from the following aspects to select complementary measures in the transformation process: first, to complement each other in terms of social structure. Social organizational structure refers to dependent social relationships within an organization or between different organizations in particular social environment in political, economic, cultural and other aspects.In traditional Chinese society, restrained by transportation and communication conditions, each district is in a closed state, society as whole lacks vitality.it somehow limited cultural development. In contemporary society, under the impact of commodity economy in the West, community members began to pursue the maximization of self-interest, which had a certain impact on economic and social development. Complement the advantages of foreign social structure with Chinese ones in the context of this society was to give full play to the advantages of Chinese and foreign culture, integrate stability and collective interests in Chinese social tradition with individual rights in the West. Secondly, complement each other in terms of social systems.Comparatively speaking, traditional Chinese society is man-ruling society, overall mindset is dominated by three principles and five virtues, while the modern social system in Western society regard society as its core in the hope that community governance can reflect the will of all members. So in the development process of contemporary Chinese culture, Chinese can integrate man-rule with social governance, fully mobilize their active ideas, make contributions to our social and cultural development.

\section{Agree to differ}

Given various cultural conflicts and exchanges, seeking common ground is an important research attitude and can have catalytic impact on the cultural transformation in China. Agree to differ is one of the most important path for contemporary social and cultural transformation.First, respecting the differences should be regard as a prerequisite for development of diversified cultures, only to recognize the difference between different types of culture, different cultures in a specific social environment can promote each other, make common progress and development. Difference is the premise of diversification in contemporary social and cultural development, respect for difference to show the personality features of culture so that different types of cultures can gain its power to grow.Second, intercultural communication between different cultures is an important way to achieve agreement on differences [4].In the context of culture globalization, different cultures worldwide will contact and exchange constantly, in this process, subjects of different cultures need in-depth benign communication to inquiry the nature of different cultures, then resolve culture gap and misunderstanding. in the process of profound analysis and understanding, take an objective view on the effect from different cultures on China contemporary culture development, and its reflected social value, then focus on development of featured national culture to maintain its advantage in the process of cultural exchange with the world so that our national culture won't be eroded by other cultures and it also have a certain influence on other cultures, facilitate modernization of contemporary Chinese culture truly.

\section{Integrated innovation}

Since the beginning of 1930s of the last century, Mr. Zhang Dainian proposed to combine Confucianism with the theory of Marxism and Leninism culture for Chinese cultural modernization and came up with important ideas of modern culture development-integrated innovation theory after a series of studies in 1980s in Korea.integrated innovation theory requires to break through and go 
beyond the paranoid mentality of national culture, and positively change closed and blind thought brought by paranoid mentality, deal with different cultures in comprehensive and innovative manner.In today society, diversified cultures are making contacts frequently, culture conflict become more obvious, people tend to have one-sided and extreme judgment over other culture with his existing culture standard, especially for culture from society where political and economic differences are huge, their culture conflict will also be more obvious, it's very easy to cause culture inferiority psychology in society with relatively backward economic and culture development, and national arrogance in society with better economic and culture development, resulting in adverse effect on culture construction.

Therefore, only under the theory of integrated innovation, keep trans- cultural mind, evaluate relevant culture objectively and impartially, aware of gaps between different cultures, can we ensure good communications between different cultures, enabling interaction and reference among multiple types of cultures for cultural development.

Core advocate of integrated innovation is cultural innovations in society with more obvious cultural conflict, and cultural innovation has an important influence on cultural heritage and development and is inexhaustible mental power to maintain a national culture in modern society for the further development [5]. Obviously, it's necessary to combine inheriting traditional culture, borrowing foreign culture and developing modern culture into one and innovate rigorously to support the development of contemporary Chinese culture and achieve modern transformation and true reconstruction of Chinese socialist culture and values, making contribution for the construction of a harmonious socialist society.

\section{Conclusion}

In summary, analysis of Chinese culture from philosophical perspective not only can inquiry philosophy connotation of Chinese culture, but also can provide theory guide from philosophy level on transformation and development of contemporary Chinese culture, achieve integrated innovative development of Chinese culture on the basis of borrowing foreign culture, inheriting traditional culture, and combining contemporary popular culture, provide culture guarantees for China Socialist modern construction.

\section{References}

[1] Yao Manlin. On Development Logic of Contemporary Chinese Culture. Journal of Taiyuan University, 2013,14 (3): 24-27.

[2] Li Qingyun. Modernization of Mao Zedong's Cultural Philosophy and Chinese Culture. Contemporary World and Socialism, 2012 (6): 82-86.

[3] Wang Shuang. Ecological Imbalances of Contemporary Chinese Culture, Beijing Jiaotong University, 2014.

[4] Yan Lianduo. Predicament and Solution of China's Contemporary Cultural Diversity. Hebei Normal University, 2009.

[5] Liu Huan. Development Strategy of Contemporary Chinese Culture under the Background of Globalization. Jiannan Literature (classics reading), 2014 (2): 489-489. 